\title{
Conservation Payments Under Risk: A Stochastic Dominance Approach
}

\author{
Pablo C. Benítez, Timo Kuosmanen, Roland Olschewski, \\ AND G. Cornelis VAN Kooten
}

\begin{abstract}
Conservation payments can be used to preserve forest and agroforest systems. To explain landowners' land-use decisions and determine appropriate conservation payments, it is necessary to focus on revenue risk. Marginal conditional stochastic dominance rules are used to derive conditions for determining the conservation payments required to guarantee that the environmentally preferred land use dominates. An empirical application to shaded coffee protection in the biologically important Chocó region of West Ecuador shows that conservation payments required for preserving shaded coffee areas are much higher than those calculated under risk-neutral assumptions. Further, the extant distribution of land has strong impacts on the required payments.
\end{abstract}

Key words: agroforest systems, conservation payments, land allocation, portfolio diversification, risk, stochastic dominance.

Forests and agroforest systems produce a variety of global environmental services, including carbon sequestration and biodiversity conservation. Without payments for these services, land uses that include forests might not be attractive for private owners. This is certainly true in the tropics, where crops and pasture have been expanded at the expense of forests (United Nations, Food and Agriculture Organization). Such conversion releases stored carbon to the atmosphere and reduces biodiversity. International payments for these services may help prevent land conversion, thereby diminishing the negative impact on the environment.

A variety of economic models have been used to evaluate the effect of land-use policies that enhance the environmental services from forests. Econometric approaches have provided insights into the aggregated impact of carbon uptake and conservation policies (Stavins; Deininger and Minten; Plantinga, Alig, and Cheng); general equilibrium models

Pablo C. Benítez is post doc researcher and G. Cornelis van Kooten is professor, Department of Economics, University of Victoria. Timo Kuosmanen is assistant professor, Environmental Economics and Natural Resources Group, Wageningen University. Roland Olschewski is assistant professor, GeorgAugust-University, Göttingen. The authors are thankful for the financial support from the German Ministry of Education and Science under the BioTEAM-Program, the Emil Aaltonen Foundation, Finland, and the Canada Research Chairs program. They also thank Henk Folmer and three anonymous journal reviewers for their valuable comments. have been used for predicting the effects of environmental payments (Callaway and McCarl); and optimal control models have strengthened knowledge concerning mitigation of climate change through forestry (Sohngen and Mendelsohn; van Kooten). But the evaluation of conservation policies rarely takes into account risk, a factor that is often decisive in allocating land uses (Collender and Zilberman; Just and Pope). In this study, therefore, we focus on farmers' land allocation problems under risk and evaluate how risk-efficient conservation policies might be used to maintain existing forest/agroforest areas.

Mean-variance (MV) analysis is a classical approach to risk management (Markowitz). Widely used in the financial world, its application is limited to situations where (1) the decision maker's utility function is quadratic or (2) the location and scale parameter condition is satisfied (Meyer). The first condition is theoretically unsatisfactory because it implies that decision makers have increasing absolute risk aversion; the second provides a broader application of MV to situations where return distributions are related to each other by location and scale. Meyer and Rasche demonstrated that this is often the case for portfolios comprising financial data, but their results have not been replicated in settings outside financial markets (Robinson and Myers). An alternative to MV analysis is the more general choice rule based on stochastic dominance 
(SD). This approach is nonparametric because it does not require explicit specification of an investor's utility function, or restrictions on the functional forms of probability distributions. SD criteria account for the entire probability distribution and employ general conditions for an investor's risk preferences. Despite the theoretical appeal of SD criteria, MV has found broader applications in empirical portfolio analysis. The main reason is that the traditional SD approach is unable to analyze situations in which portfolio diversification is possible, and identify if a given portfolio is efficient under SD criteria (Levy 1992,1998). Recent developments of SD theory enable researchers to address problems dealing with portfolio diversification (Shalit and Yitzhaki; Kuosmanen; Post).

As in the case of portfolio diversification, the application of SD to farm diversification problems has been limited. If land can be freely apportioned into smaller plots and used for different crops, this provides opportunity for the farmer to decrease income volatility in the same way that an investor diversifies a portfolio by choosing different securities. Traditional SD applications in agricultural economics (Cochran, Robinson, and Lodwick; Barley and Richardson; Klemme) have been criticized for ignoring farm diversification possibilities. McCarl et al. demonstrated that SD comparisons of unmixed alternatives might lead to wrong results when land uses are not mutually exclusive. In particular, if the return series for different land uses have little correlation, farmers could hedge their risks by diversifying, with a portfolio consisting of mixed land uses potentially preferred in the SD sense.

So far, there are few (if any) applications of SD theory in situations where farm diversification is possible. In this study, we develop a methodological basis for such SD applications, based on recent theoretical advances, and determine the conditions under which the preservation of forest and agroforest systems would be part of an efficient portfolio.

We begin our investigation with a brief review of stochastic dominance rules. We then provide a theoretical framework for the determination of risk-efficient conservation payments under different SD criteria. The theoretical model is applied to a West Ecuador case study. The study area is described, relevant data are provided, and major findings of the empirical application are discussed. Some conclusions follow.

\section{Stochastic Dominance Rules}

\section{Farms with Mutually Exclusive Land Uses}

Assume that a landowner must decide whether to invest in forestry/agroforestry, $f$, or some crop, $g$, with cumulative net revenue distribution functions given by $F(x)$ and $G(x)$, respectively. Forestry dominates the crop alternative by first-order stochastic dominance (FSD) iff

$$
\begin{aligned}
& G(x)-F(x) \geq 0, \quad \forall x \in R, \\
& \quad \text { with at least one strict inequality. }
\end{aligned}
$$

The FSD criterion has an intuitive interpretation in terms of the von NeumannMorgenstern expected utility theory: if one investment alternative dominates another, every nonsatiated investor (with nondecreasing utility function, $U^{\prime} \geq 0$ ) will prefer the dominant alternative. While this criterion seems reasonable, it is not very discerning. In practice, the cumulative distributions of net returns of the two investment alternatives often intersect, in which case FSD cannot discriminate between the alternatives.

If investors are risk averse in addition to insatiable (i.e., $U^{\prime} \geq 0$ and $U^{\prime \prime} \leq 0$ ), second-order stochastic dominance (SSD) could be used to choose between investment alternatives. Formally, forestry dominates cropping in the SSD sense iff

$$
\int_{-\infty}^{x}(G(z)-F(z)) d z \geq 0 \quad \forall x \in R,
$$

with at least one strict inequality.

In words, SSD requires that the area under the cumulative density function for forestry is always smaller than the area under the cumulative density function for the crop. Every risk-averse, nonsatiable investor prefers the investment alternative that is dominated by SSD.

In empirical analysis, the probability distributions $G$ and $F$ are unknown and must be estimated from available data. Hence, we consider a finite, discrete sample of observations on returns in forestry and a crop alternative over $T$ periods, which we interpret as states of nature. We assume the states are drawn randomly with replacement from a common pool of possible states. These are assumed to be identically and independently distributed such that each observed state is equally likely to occur in any period, and the occurrence of a state in one 
period does not influence the probability distribution in any other period.

Standard algorithms for identifying stochastic dominance utilize pair-wise comparisons of sorted series of net revenue distributions (Levy 1992, 1998). Denote original time series of net revenues from forestry and cropping by $\mathbf{y}_{f}$ and $\mathbf{y}_{g}$, respectively, and the vectors of the rearranged series sorted in ascending order by $\mathbf{x}_{f}$ and $\mathbf{x}_{g}$. From the sorted revenue series, we construct the cumulative sum vector $\mathbf{x}_{f}^{\prime}$ with elements $i$ as

$$
x_{f, i}^{\prime}=\sum_{k=1}^{i} x_{f, k} .
$$

The same procedure is used to obtain $x_{g}^{\prime}$. We can now express the empirical SD rules as follows (Levy 1992):

\section{FSD: Forestry dominates cropping}

$$
\text { iff } x_{f, i} \geq x_{g, i} \quad \forall i=1, \ldots, T
$$

SSD: Forestry dominates cropping

$$
\text { iff } x_{f, i}^{\prime} \geq x_{g, i}^{\prime} \quad \forall i=1, \ldots, T
$$

with at least one strict inequality holding in both cases.

\section{Farms with Diversification Possibilities}

The pair-wise comparison of empirical revenue distributions applies to situations where land-use alternatives are mutually exclusive. If farmers diversify their production, the rules based on pair-wise comparisons fail to account for the infinite number of different landuse portfolios. Using portfolio weights $\mathbf{w}=$ $\left(w_{f}, w_{g}\right)$ for forestry and cropping, the revenue portfolios are represented by the vector $\mathbf{y}_{p}=w_{f} \mathbf{y}_{f}+w_{g} \mathbf{y}_{g}$. The key to the empirical application of SD rules under portfolio diversification is to preserve the cross-sectional structure of revenues, because it is impossible to recover portfolio returns from the sorted revenue series; for example, $w_{f} \mathbf{y}_{f}+w_{g} \mathbf{y}_{g} \neq$ $w_{f} \mathbf{x}_{f}+w_{g} \mathbf{x}_{g}$ (see Kuosmanen). That is, when series are first sorted according to each series' revenues and portfolio revenues are estimated given $\mathbf{w}$, it is possible to get portfolios consisting of crop revenues of different years (say a portfolio consisting of $50 \%$ of year 1990 coffee with $50 \%$ of year 2000 maize), and that is unreasonable. Therefore, an alternative criterion is required to sort the series.
Shalit and Yitzhaki and Post, propose to sort all revenue series according to the portfolio returns $\mathbf{y}_{p}$, such that portfolio returns are in ascending order. Denote the resulting sorted portfolio revenue series by $\mathbf{x}_{p}^{\mathbf{w}}$, and the revenue series for forestry and cropping, sorted according to the portfolio revenues, by $\mathbf{x}_{f}^{\mathbf{w}}$ and $\mathbf{x}_{g}^{\mathbf{w}}$, respectively. While elements of $\mathbf{x}_{p}^{\mathbf{w}}$ are in ascending order, the elements of $\mathbf{x}_{f}^{\mathbf{w}}$ and $\mathbf{x}_{g}^{\mathbf{w}}$ are usually not. The rationale for sorting all series according to the portfolio returns is to guarantee that $\mathbf{x}_{p}=w_{f} \mathbf{x}_{f}+w_{g} \mathbf{x}_{g}$.

Following Shalit and Yitzhaki, we apply SD rules (4) and (5) to revenue series sorted according to the portfolio revenues rather than separately for each crop, to get the so-called marginal conditional stochastic dominance (MCSD) rules. Again, we form the cumulative sum vectors $\mathbf{x}_{f}^{\mathbf{w} \prime}$ and $\mathbf{x}_{g}^{\mathbf{w} \prime}$, as in (3). The first- and second-order marginal conditional stochastic dominance (FMCSD and SMCSD) rules are defined as follows: ${ }^{1}$

$$
\begin{aligned}
\text { FMCSD: } & \text { Forestry dominates cropping } \\
& \text { iff } x_{f, i}^{\mathbf{w}} \geq x_{g, i}^{\mathbf{w}} \quad \forall i=1, \ldots, T
\end{aligned}
$$

SMCSD: Forestry dominates cropping

$$
\text { iff } x_{f, i}^{\mathbf{w} \prime} \geq x_{g, i}^{\mathbf{w} \prime} \quad \forall i=1, \ldots, T
$$

with at least one strict inequality holding in both cases.

Shalit and Yitzhaki show that, if an asset (here forestry) dominates another asset (crop) by SMCSD, every nonsatiated riskaverse landowner (investor) will be better off if the portfolio weight of the dominating asset is increased at the expense of the dominated asset. One can verify that FMCSD implies that every nonsatiated landowner (irrespective of risk preferences) will benefit from an increase in the portfolio weight of the dominating asset at the expense of the dominated asset.

\section{Stochastic Dominance for Determining Conservation Payments}

Suppose the owner of forest/agroforest land considers converting the land to an alternative use. Three mutually exclusive situations can be distinguished:

\footnotetext{
${ }^{1}$ Shalit and Yitzhaki only consider the second-order MCSD rule. The first-order MCSD rule is an innovation made here.
} 
(a) Forestry is not a risk-efficient land use: At least one land-use alternative dominates forestry, and retaining forests is suboptimal. Complete deforestation is likely to occur.

(b) Forestry is a risk-efficient land use, but not the only one: Depending on landowner preferences, a part of the farm-forest will be converted to alternative uses. Partial deforestation is likely to occur.

(c) Forestry is the only risk-efficient land use: Forestry dominates all alternative land uses, thereby guaranteeing that all existing forests are kept-no deforestation is likely.

By introducing a conservation payment, $s$, the authority influences occurrence of $(a),(b)$, or (c). The minimum payment required to ensure that forestry is not dominated by another land use (i.e., the limiting case between $(a)$ and $(b)$ ) is denoted by $s_{\min }$. It can also be interpreted as the maximum payment for which alternative (a) (total deforestation) remains the optimal strategy. Similarly, the minimum payment required to guarantee that forestry dominates all other land uses, with all landowners finding forestry the optimal expected utility maximizing land use (i.e., the limiting case between $(b)$ and $(c)$ ) is denoted by $s_{\max }$. The values $s_{\min }$ and $s_{\max }$ represent the extreme boundary points for the range of possible conservation payments: any payment below $s_{\min }$ will have no effect on conservation, whereas any payment above $s_{\max }$ will have no additional conservation benefit. In both cases, financial resources would be wasted. Therefore, a rational conservation authority should always choose a payment within the range $\left(s_{\min }, s_{\max }\right)$.

If we knew these bounds at the microlevel of individual farms or plots, it would be possible to map out the upper and lower boundaries of a supply curve for nature conservation in a nonparametric fashion. Specifically, one could arrange the $s_{\min }$ and $s_{\max }$ values for different plots of land in ascending order, accumulate the land areas from the smallest $s_{\min }\left(s_{\max }\right)$ to the largest, and plot the cumulative land area on the horizontal axis with the $s_{\min }$ and $s_{\max }$ values on the vertical axis. Given a target level for total land area to be conserved, we could use such supply curves to estimate a range for the necessary conservation payment, and identify which parcels of land would be most likely to fall under conservation.
Alternatively, we could estimate the $s_{\min }$ and $s_{\max }$ values at a more aggregated regional level, thereby providing a conservation agency with a crude but relatively inexpensive preliminary check on the feasibility of conservation in that region. We illustrate this approach in more detail below using shaded coffee in Ecuador.

The stochastic dominance approach provides a framework for estimating the $s_{\min }$ and $s_{\max }$ values, assuming either mutually exclusive land uses or farm diversification. Given that both settings can be observed in practice, we evaluate both before considering our case study.

\section{Farms with Mutually-Exclusive Land Uses}

In order to find $s_{\min }$ and $s_{\max }$ under FSD, we recognize that nonstochastic conservation payment shifts the cumulative distribution function of forestry returns to the right. Thus, each $x_{f, i}$ from forestry is now $x_{f, i}+s$. Using FSD conditions (4), we get ${ }^{2}$

$$
\text { FSD: } \begin{aligned}
s_{\min } & =\min _{i}\left(x_{g, i}-x_{f, i}\right) \quad \text { and } \\
s_{\max } & =\max _{i}\left(x_{g, i}-x_{f, i}\right) .
\end{aligned}
$$

Similarly, using (5) we get for SSD

$$
\begin{aligned}
\mathrm{SSD}: s_{\min } & =\min _{i}\left(\frac{x_{g, i}^{\prime}-x_{f, i}^{\prime}}{i}\right) \text { and } \\
s_{\max } & =\max _{i}\left(\frac{x_{g, i}^{\prime}-x_{f, i}^{\prime}}{i}\right) .
\end{aligned}
$$

Since we know that negative payments are not possible, all equations for $s_{\min }$ and $s_{\max }$ are truncated at zero.

The level of payment for a risk-neutral landowner, for whom $s_{\max }=s_{\min }=E\left(x_{g, i}-x_{f, i}\right)$, lies between the FSD limits. The upper and lower bounds in SD analysis emerge due to heterogeneity of landowners' preferences. If all of them had the same utility function, we would have $s_{\max }=s_{\min }$ based on direct expected utility analysis. If we know little about their utility function, as in FSD, we expect a broad range between $s_{\max }$ and $s_{\min }$. Further knowledge of the utility function (e.g., $U^{\prime \prime} \leq 0$, making SSD valid) narrows this payment range.

The conditions for $s_{\min }$ and $s_{\max }$ could be extended to cases where more than one alternative land use exists. By comparing forestry with each of the alternative land uses, we obtain a

\footnotetext{
${ }^{2} \mathrm{~A}$ formal proof is available from the authors upon request.
} 
single $s_{\max }$ and $s_{\min }$ for each comparison. The overall $s_{\max }$ is the maximum of all the individual $s_{\max }$, and the overall $s_{\min }$ is the maximum of all the individual $s_{\min }$. We could also interpret these payments as measures of the efficiency of land use $f$. Large values of (overall) $s_{\min }$ represent land uses that are least risk efficient, while small values of (overall) $s_{\max }$ represent risk-efficient land uses that nearly dominate all other land uses. $^{3}$

\section{Farms with Diversification Possibilities}

The minimum and maximum bounds determined so far pertain to the case where all land is assigned a single use. Applying the previous insights to the FMCSD criteria, we get the following minimum and maximum payments:

$$
\begin{aligned}
\text { FMCSD: } & s_{\min }=\min _{i}\left(x_{g, i}^{\mathbf{w}}-x_{f, i}^{\mathbf{w}}\right) \text { and } \\
s_{\max } & =\max _{i}\left(x_{g, i}^{\mathbf{w}}-x_{f, i}^{\mathbf{w}}\right) .
\end{aligned}
$$

Similarly, the minimum and maximum payments under SMCSD are

$$
\begin{aligned}
\text { SMCSD: } & s_{\min }=\min _{i}\left(\frac{x_{g, i}^{\mathbf{w} \prime}-x_{f, i}^{\mathbf{w} \prime}}{i}\right) \text { and } \\
s_{\max } & =\max _{i}\left(\frac{x_{g, i}^{\mathbf{w} \prime}-x_{f, i}^{\mathbf{w} \prime}}{i}\right) .
\end{aligned}
$$

Note the similarity of these conditions with those for FSD and SSD. The only difference is that here the series are sorted according to portfolio revenues. The FMCSD (SMCSD) conditions give the minimum and maximum bounds for the conservation payment to guarantee that all nonsatiated (and risk-averse) landowners have no incentive at the margin to increase the weight of cropping in the land portfolio. If there is only one alternative crop $g$, these bounds fully exhaust the diversification options. However, if there are multiple alternative crops (say $g$ and $h$ ), the bounds should be constructed so that there is no portfolio of alternative crops that dominates forestry in the sense of MCSD.

\footnotetext{
${ }^{3}$ Here we find an advantage of using SD instead of the traditional MV approach. Under SD, we always have a clear answer of how much the $s_{\min }$ and $s_{\max }$ bounds should be, but under MV there are situations where the $s_{\max }$ bound cannot be estimated. Suppose forestry has a higher variance than cropping. No matter how large the conservation payment for forestry, the MV approach is unable to tell us that forestry is unambiguously better than cropping, so $s_{\max }$ remains uncertain.
}

Since the current portfolio weights are denoted by $\mathbf{w}$, we use $v_{\mathrm{g}}$ and $v_{h}$ as the portfolio weights of crops $g$ and $h$ in the subportfolio that threatens to replace forestry as the land use. To take the diversification options fully into account, we need to solve the following max-min and max-max problems:

FMCSD:

$$
\begin{aligned}
& s_{\min }=\max _{v_{g}, v_{h}}\left[\min _{i}\left(\left(v_{g} x_{g, i}^{\mathbf{w}}+v_{h} x_{h, i}^{\mathbf{w}}\right)-x_{f, i}^{\mathbf{w}}\right)\right] \\
& \text { and } \\
& s_{\max }=\max _{v_{g}, v_{h}}\left[\max _{i}\left(\left(v_{g} x_{g, i}^{\mathbf{w}}+v_{h} x_{h, i}^{\mathbf{w}}\right)-x_{f, i}^{\mathbf{w}}\right)\right]
\end{aligned}
$$

SMCSD:

$$
s_{\min }=\max _{v_{g}, v_{h}}\left[\min _{i} \frac{1}{i}\left(\left(v_{g} x_{g, i}^{\mathbf{w} \prime}+v_{h} x_{h, i}^{\mathbf{w \prime}}\right)-x_{f, i}^{\mathbf{w} \prime}\right)\right]
$$

and

$$
s_{\max }=\max _{v_{g}, v_{h}}\left[\max _{i} \frac{1}{i}\left(\left(v_{g} x_{g, i}^{\mathbf{w \prime}}+v_{h} x_{h, i}^{\mathbf{w} \prime}\right)-x_{f, i}^{\mathbf{w} /}\right)\right]
$$

subject to $v_{g}+v_{h}=1$ and $v_{g}, v_{h} \geq 0$. In practice, these bounds can be found by solving the linear programming (LP) problems in the Appendix.

\section{Case Study: Shaded Coffee in West Ecuador}

In this section, we apply our theoretical developments to the conservation of a shaded coffee, agroforest system in a developing country. Compared to a monocultural land use, this system is richer in biodiversity (Perfecto et al.) albeit economically less attractive. The example provides a practical demonstration of our approach, but one that can only be considered a crude guide for policy makers because of the poor quality of our data.

The study area is in the province of Manabí, located in the tropical lowlands of West Ecuador. The natural vegetation is a continuation of the El Chocó, a biogeographical region known as one of the world's biodiversity hotspots because of its species richness, high levels of endemism, and stress from human activities (Myers et al.). Primary forests remain mostly in protected areas such as the Mache Chindul Reserve and the Machalilla National Park. Important areas of coffee plantations are found throughout Manabí, which constitutes one of the main regions of coffee production 
under shade. While state and private actions increasingly protect primary forests, shaded coffee systems that provide a buffer zone for biodiversity protection are being cleared. Government estimates suggest that coffee plantations have been reduced nationally by about $40 \%$ during the last decade (SICA).

We consider four land-use alternatives: shaded coffee, upland rice, maize, and pasture for dairy cows and cattle. Time series for estimating yearly revenues are available for 1967-2002 from several government offices in charge of agricultural statistics. For coffee, rice, and maize yield, we have data for 1991-2002 (SICA) and 1967-90 (MAG), respectively. ${ }^{4}$ Since these series correspond to country-level yield data, we convert them to provincial yields based on factors obtained from the 2000 census (INEC, MAG, and SICA). For dairy and cattle, we assume constant yields over time. This approximation is valid because farmers are able to mitigate weather risks that affect cattle growth. During unexpected dry seasons farmers can move cattle temporarily to other parcels, for example, but a farmer growing maize or rice has few alternatives during an unanticipated drought. Cattle yield is estimated using a method described by Benítez et al. For the stocking density of 1.1 head per ha found in Manabí province, the estimated growth in cattle live weight yield is $93 \mathrm{~kg}$ per year, while a dairy cow in this region yields 2.6 liters of milk per day (INEC, MAG, and SICA). Since $41 \%$ of the livestock herd consists of cows and $40 \%$ of them produce milk, annual production is calculated to be $172 \mathrm{l} / \mathrm{ha}$.

Producer prices for crops are available for the periods 1991-2002 (SICA) and 1978-90 (Whitaker, Colyer, and Alzamora). For the period 1967-1977, we estimate producer prices as a function of retail prices (INEC). In 2000, the local currency (sucre) was officially eliminated and replaced by the U.S. dollar, which had a strong effect on inflation. To reduce the impact of monetary policies and dollarization on profit distributions, we estimated net revenues in constant year 2000 US dollar based on Ecuador's consumer price index (INEC). Prices before 2000 are first converted into constant (year 2000) sucre and then transformed into U.S. dollars using the 2000 exchange rate;

\footnotetext{
${ }^{4}$ Data sources are from different publications, but most of the primary data on crop yield and prices were collected by the Dirección de Información Agropecuaria of the Agricultural Ministry. This work has been complemented in the last few years by the World Bank's SICA project, which attempts to improve information management and dissemination.
}

dollar prices after 2000 are converted into constant U.S. dollars using the CPI.

Cost estimates are based on survey data from 2003. For coffee, costs include land preparation, planting, cleaning, pruning, and shade control. Land preparation and planting costs are annualized using a discount rate of $5 \%$ and a period of fifteen years. ${ }^{5}$ For annual crops (maize and rice), costs include land preparation, seeds, planting, fertilizer, weeding, and pest control. These costs are the same (in real terms) for all years except for seed costs, which depend on annual crop prices. Variable costs include harvest and transport costs. For cattle, costs include brush control, the opportunity costs of cattle stock, cattle losses, vaccines, and pest control. The opportunity costs of cattle and costs associated with cattle losses also depend on annual (cattle) prices. General farm costs such as administration and fence maintenance are not included, since they have no influence on land-use choice. Based on this information, we estimate net revenues for each year as the product of price and yield minus costs.

\section{Revenue Trends}

$\mathrm{SD}$ analysis is based on the assumption that each observed state of nature is equally likely to occur and that the probabilities do not change over time. This assumption is not valid if revenue follows a time trend, as is the case if crop yield $(q)$ is a function of time $(t)$,

$$
q_{t}=a+b t+e_{t}
$$

Then expected returns depend on time in contrast to the assumption that returns are equally likely to occur. Returns can be de-trended, however, before determining the SD of a series. A series can be de-trended using, among others, first differencing, digital filtering, and piece-wise polynomials. We employ the most common procedure of curve fitting. We first test for the existence of significant trends in the yields and prices of each of the four land uses by testing if the coefficient $b$ in (14) is statistically significant. ${ }^{6}$ Results indicate that maize yields have an increasing trend and rice

\footnotetext{
${ }^{5}$ Coffee has been grown on some parcels for upward of eighty years, although plants have been renewed periodically.

${ }^{6}$ Testing yield and price separately is adequate given the small correlation between the two series in the case of rice, maize, and pasture. For coffee, there is some correlation between price and yield (correlation coefficient is 0.16 ), so we also tested trends in net revenue.
} 
Table 1. Tests for Trends in Series for Rice Price and Maize Yield, Manabí, 1967-2002

\begin{tabular}{|c|c|c|c|c|}
\hline Model & $R^{2}$ & $\begin{array}{c}\text { White Hetero., } \\
\text { No Cross Terms, } \\
p \text {-Value }\end{array}$ & $\begin{array}{c}\text { Breusch-Godfrey } \\
\text { Serial Correlation } \\
\text { Test, } 2 \text { lags, } \\
p \text {-Value }\end{array}$ & $\begin{array}{l}\text { J. Bera Test, } \\
p \text {-Value }\end{array}$ \\
\hline \multicolumn{5}{|l|}{ Rice price } \\
\hline Linear trend & 0.407 & 0.376 & 0.08 & 0.069 \\
\hline Logarithm trend & 0.278 & 0.611 & $0.01 *$ & 0.173 \\
\hline \multicolumn{5}{|l|}{ Maize yield } \\
\hline Linear trend & 0.658 & $0.00004^{*}$ & 0.2 & 0.394 \\
\hline Logarithm trend & 0.492 & $0.034^{*}$ & $0.0048^{*}$ & $0.01^{*}$ \\
\hline
\end{tabular}

* Significant at the $5 \%$ confidence level or better.

Table 2. Summary Statistics for Net Revenues Series of Land-Use Systems in Manabí, 1967-2002

\begin{tabular}{llccc}
\hline & Coffee & Maize $^{*}$ & Rice* $^{*}$ & Pasture \\
\hline Mean (2000 US\$/ha) & 78 & 108 & 57 & 53 \\
Standard deviation (2000 US\$/ha) & 86 & 56 & 61 & 18 \\
Skewness & 1.6 & 0.5 & 0.7 & 0.7 \\
Kurtosis & 6.5 & 3.5 & 2.8 & 2.3 \\
Jarque-Bera $p$-value & 0.000 & 0.4 & 0.2 & 0.2 \\
Shapiro-Wilk. $p$-value & 0.01 & 0.5 & .07 & 0.01 \\
\hline
\end{tabular}

*De-trended series.

prices a decreasing trend; both are statistically significant at the $5 \%$ level.

It is reasonable to expect that the increase in land productivity due to technological improvements (e.g., development of new seeds) has its limits and that growth in yield should decline over time. Nor can prices fall continuously. Therefore, a concave trend function (in our case logarithmic) is considered in addition to a linear trend, and both trend functions are tested (table 1). Diagnostic tests of the residuals include White's heteroskedasticity test, Breusch-Godfrey Serial Correlation Test, and the Jarque Bera test for normality. Based on $R^{2}$ and diagnostic tests of the residuals, we select a linear model for both rice and maize. ${ }^{7}$ We detrend the series by adding the residuals of the linear regression to the expected value of equation (14) at time $T$. In this way, the trends of the series are eliminated and our expectations at time $T$ coincide with the expected value of the series.

Once the price and yield series are corrected for trend, we reestimate net revenues. The

\footnotetext{
${ }^{7}$ For maize, yield heteroskedasticity is ignored, which suggests that a more complex trend model might be more appropriate. We retain the linear model, however, because of its simplicity and relatively high $R^{2}$, and to be consistent with the other series.
}

descriptive statistics for the net revenue series, including the Jarque-Bera and Shapiro-Wilk tests for normality, are provided in table 2. Nonnormality is particularly evident for coffee and it is caused by both positive skewness and high kurtosis. This motivates the use of the SD approach, which is valid for any type of distribution.

\section{Bootstrapping}

Bootstrapping has been used to increase the power of empirical applications of stochastic dominance tests. One of the advantages is that bootstrapping smoothes the cumulative density function (CDF) in a way that mitigates problems associated with obtaining reliable estimates of order statistics (Nelson and Pope). For example, sample error might lead to estimating order statistics above (or below) the real CDF. By repetitive resampling with replacement, bootstrapping smoothes such "highs" and "lows" and allows SD tests to be more discerning as it avoids inadvertent intersection of cumulative distributions.

A simple bootstrapping algorithm based on Nelson and Pope is employed. We first resample with replacement from the original empirical distribution function (EDF) and then find 


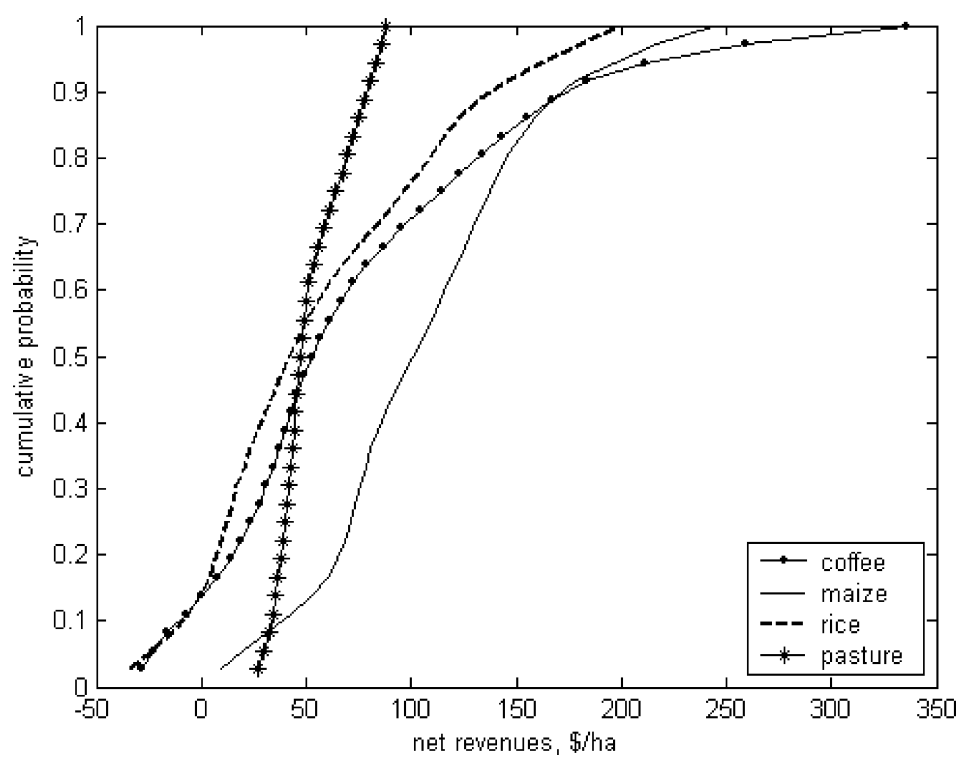

Figure 1. Bootstrapped EDFs for major land uses in west ecuador

the average of each order statistic for computing a new EDF. The number of samples needs to be sufficiently large (we used 1,000 sample), so that the resulting distribution will not be affected by additional resampling. Irregularities are eliminated and the bootstrapped distribution is assumed to be the appropriate one for estimating the risk-efficient conservation payments under FSD and SSD.

\section{Results and Discussion}

We now estimate the risk-efficient conservation payments under conditions of mutually exclusive land-use alternatives and when full portfolio diversification is allowed.

\section{Farms with Mutually Exclusive Land Uses}

The FSD-efficient land-use alternatives can be determined by direct observation of the intersections of the (bootstrapped) EDFs of the different land uses (figure 1). The EDF for maize is always to the right of that of rice, indicating that maize dominates rice by FSD. Since the EDFs for coffee, pasture, and maize all intersect, the FSD-efficient set contains these three land uses. To rank the other land uses requires further differentiation, which we do using SSD.

Since maize dominates rice by FSD, it also dominates rice by SSD. Maize dominates coffee and coffee dominates rice by SSD, but there is no dominance relation between maize and pasture. Thus, the SSD-efficient set consists of maize and pasture. These results explain some of the land-use choices in the study region, particularly the conversion of existing shaded coffee areas.

Finding the risk-efficient payment for conservation requires estimates of $s_{\min }$ and $s_{\max }$ that, in turn, depend on the alternative landuse opportunities. We calculate the minimum and maximum bounds required for making coffee a risk-efficient land-use alternative, comparing coffee returns separately with each alternative land use. The results are reported in table 3. Since coffee is FSD efficient, the lower bound $s_{\min }$ is equal to zero in the FSD case. The upper bound $s_{\max }$ varies between $\$ 2 /$ ha and $\$ 55 /$ ha per annum. In the SSD case, the minimum conservation payment required is $\$ 30 / \mathrm{ha}$ (to break SSD dominance by maize). The maximum payment is $\$ 55 / \mathrm{ha}$, which would suffice to guarantee that coffee dominates all other alternatives.

These payments can be compared with those required under risk neutrality, where only expected values matter. Interestingly, a risk-neutral landowner would be indifferent between coffee and maize if paid a conservation payment of $\$ 30 / \mathrm{ha}$, which turns out to be equal to the corresponding $s_{\min }$ value. When we compare coffee with pasture or rice, there is no need for a payment under risk-neutral conditions as the mean net return to coffee is higher. However, to ensure that all risk-averse 
Table 3. Minimum and Maximum Conservation Payments Required to Make Coffee a Risk-Efficient Land Use (Year 2000 US\$ per ha)

\begin{tabular}{|c|c|c|c|c|c|c|}
\hline \multirow[b]{3}{*}{ Decision Criteria } & \multicolumn{6}{|c|}{ Land Use Alternative to Coffee } \\
\hline & \multicolumn{2}{|c|}{ Maize } & \multicolumn{2}{|c|}{ Rice } & \multicolumn{2}{|c|}{ Pasture } \\
\hline & $\mathrm{s}_{\min }$ & $\mathrm{s}_{\max }$ & $\mathrm{s}_{\min }$ & $\mathrm{s}_{\max }$ & $\mathrm{s}_{\min }$ & $\mathrm{s}_{\max }$ \\
\hline FSD & 0 & 53 & 0 & 2 & 0 & 55 \\
\hline SSD & 30 & 48 & 0 & 0 & 0 & 55 \\
\hline $\begin{array}{l}\text { Difference in means } \\
\text { (Risk neutrality assumption) }\end{array}$ & 30 & 30 & 0 & 0 & 0 & 0 \\
\hline
\end{tabular}

Note: A value of zero is assigned when the estimated payment is negative.

landowners prefer coffee over pasture may require a payment as great as $\$ 55 /$ ha (based on SSD). Such a risk premium represents $70 \%$ of the average net revenues for coffee. This suggests it is the high variability of coffee revenues that discourages risk-averse landowners from growing shaded coffee, even though expected coffee revenues are competitive with returns to other land uses.

These results stress the need for considering risk when implementing conservation policy instruments. In the present case, offering a conservation payment of $\$ 30 /$ ha to cover the difference in expected revenues between maize and coffee would likely prove ineffective as a conservation policy, because farmers would still have to bear the greater risk associated with coffee returns.

\section{Farms with Diversification Possibilities}

In this section we first illustrate the MCSD concept using an arbitrary equally weighted (50-50) portfolio of coffee and maize and then determine risk-efficient payments under MCSD based on existing land-use shares in West Ecuador. To illustrate the concept of FMCSD, cumulative probabilities of net revenues with a portfolio consisting of coffee $\mathbf{x}_{f}^{w}$ and maize $\mathbf{x}_{g}^{\mathbf{w}}$, as well as their respective components, are provided in figure 2 (panel A). (The axes in the figure have been reversed for better presentation.) One land use dominates another under FMCSD if there is no intersection of the individual land-use curves. As shown in the figure, both curves intersect, so we conclude that there is no FMCSD between coffee and maize for such a portfolio. The cumulative series for determining SMCSD are indicated in panel B, figure 2. Since the series for maize are always above those of coffee, maize dominates coffee by SMCSD. We conclude that second-order dominance does exist.

To estimate the efficient conservation payments under the MCSD criteria, we interviewed 92 coffee producers, finding that $35 \%$ of them do not diversify their land use. The remainder employ different combinations of land uses that, on average, have the portfolio shares shown in table 4. As in the case of no diversification, we estimate risk-efficient conservation payments that prevent conversions of shaded coffee to other uses at the margin. These results are also summarized in table 4, where $s_{\min }$ and $s_{\max }$ payments under FMCSD and SMCSD are provided.

The results confirm the theoretical expectation that the level of a risk-efficient payment depends on the given portfolio shares. In most of the portfolios analyzed, the payment $s_{\max }$ under MCSD is higher than under SSD. Importantly, under SSD and SMCSD, the minimum payment $s_{\min }$ is often the difference in expected net returns between coffee and maize. To understand this peculiarity, note that a payment $s_{\min }$ requires breaking the dominance of maize over coffee. Since the distribution of coffee has a greater spread than that of maize, this dominance can only be broken by adding a payment that results in both land uses having the same mean. Then maize can never dominate coffee by SSD.

\section{Discussion}

Conservation agencies aim to engage farmers whose land uses provide the highest biodiversity, carbon sequestration, and watershed benefits. In West Ecuador, such land use is shaded coffee, which is also the most risky alternative. As a result, conservation payments need to be higher than would be the case if farmers 


\section{Panel A}

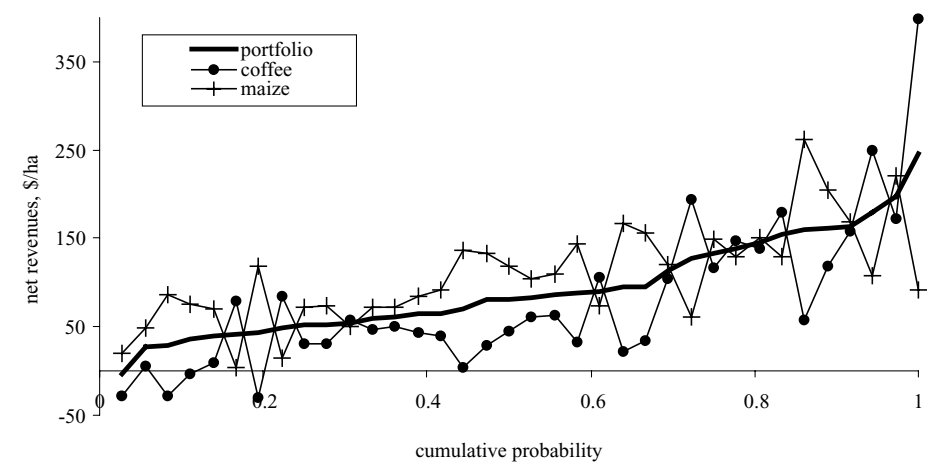

Panel B

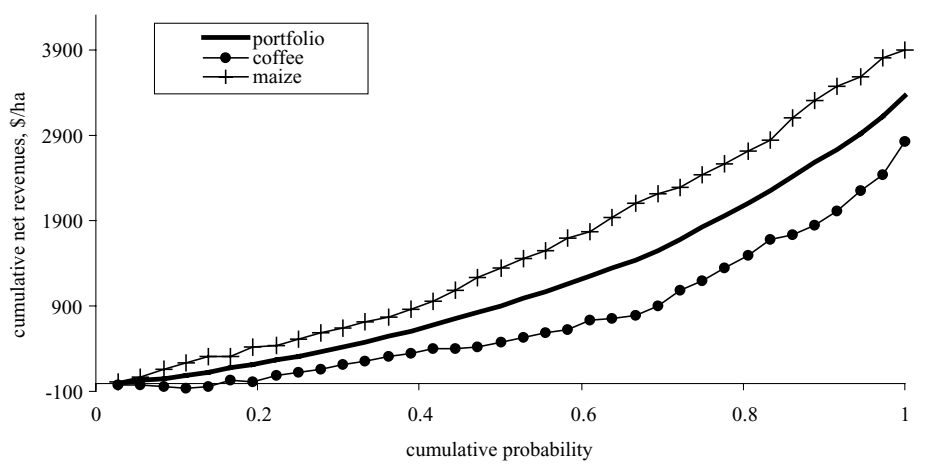

Figure 2. Graphical illustration of FMCSD (panel A) and SMCSD (Panel B)

were risk neutral. ${ }^{8}$ Determining the $s_{\min }$ and $s_{\max }$ bounds can prove an inexpensive preliminary check for the conservation agency. One has to pay at least $s_{\min }$ to get any results. If $s_{\min }$ is already considered too high, conservation efforts should concentrate on areas with lower opportunity costs. Further, the conservation agency should never end up paying more than $s_{\max }$. If this is less than what coffee consumers might be willing to pay for coffee produced in a biodiversity-rich fashion, then the project should go ahead.

When the interval $s_{\min }-s_{\max }$ is large, a more thorough investigation of farmers' risk preferences is needed. As an illustration, consider the impact of the degree of risk aversion in a hypothetical situation where farmers' prefer-

\footnotetext{
${ }^{8}$ There are cases when the conservation agency wants to engage farmers on the less-risky alternative and this could result on smaller payments than those under risk neutrality. For instance, in the Ecuadorian highlands, small risk-free payments for preserving the evergreen montane forest and the páramo are sufficient to encourage farmers to stop more risky cropping alternatives like potato growing (Echavarria et al.).
}

ences are represented by an exponential utility function $u(x)=-\exp (-\rho x)$; coefficient $\rho$ can be interpreted as the Arrow-Pratt measure of absolute risk aversion. When land uses are mutually exclusive, the optimal payment for conservation is the minimum payment that allows agroforest to have at least the same expected utility as the second-best alternative land use. Figure 3 shows the required payment for preserving shaded coffee in West Ecuador under different degrees of risk aversion, ranging from risk-neutral ( $\rho$ close to 0 ) to highly riskaverse $(\rho=0.015)$ landowners. ${ }^{9}$

The required payments are always located between the $s_{\min }$ and $s_{\max }$ bounds. For this utility function, the optimal payment comes close to the $s_{\min }$ value at low levels of absolute risk aversion. However, the optimal payment remains well below $s_{\max }$ even for the highest levels of absolute risk aversion; in order to

\footnotetext{
${ }^{9}$ Holt and Laury suggest a coefficient of relative risk aversion $(\gamma)$ of 1.2 for representing highly risk-averse decision makers. This corresponds to an absolute risk aversion of 0.016 , given that $\rho=$ $\gamma / x$, and using $x=75$ as average net revenues for all land uses.
} 
Table 4. Required Payments for Shaded Coffee Conservation based on Responses from 60 Interviewed Coffee Producers with Diversified Farms (Year 2000 US\$ per ha)

\begin{tabular}{|c|c|c|c|c|}
\hline \multirow[b]{3}{*}{ Land-Use Shares of Representative Farms } & \multicolumn{4}{|c|}{ Decision Rule } \\
\hline & \multicolumn{2}{|c|}{ FMCSD } & \multicolumn{2}{|c|}{ SMCSD } \\
\hline & $\mathrm{s}_{\min }$ & $\mathrm{S}_{\max }$ & $\mathrm{s}_{\min }$ & $\mathrm{s}_{\mathrm{ma}}$ \\
\hline \multicolumn{5}{|l|}{ Farms with two land uses } \\
\hline Coffee: $56 \%$; Pasture: $44 \%$ & 0 & 77 & 0 & \\
\hline Coffee:55\%; Rice:45\% & 0 & 107 & 0 & 46 \\
\hline Coffee: $79 \%$; Maize: $21 \%$ & 0 & 204 & 30 & 104 \\
\hline \multicolumn{5}{|l|}{ Farms with three land uses } \\
\hline Coffee: $36 \%$; Rice: $11 \%$; Pasture: $53 \%$ & 0 & 107 & 0 & \\
\hline Coffee: $47 \%$; Maize: $15 \%$; Pasture: $38 \%$ & 0 & 204 & 30 & 104 \\
\hline Coffee: $68 \%$; Maize: $20 \%$; Rice: $12 \%$ & 0 & 204 & 30 & 104 \\
\hline \multicolumn{5}{|l|}{ Farms with four land uses } \\
\hline Coffee: 34\%; Maize: 6\%; Rice:9\%; Pasture: 51\% & 0 & 204 & 30 & 111 \\
\hline
\end{tabular}

Note: A value of zero is assigned when the estimated payment is negative.

attain $s_{\text {max }}$, some other type of utility function is required. Interestingly, even if we made a fairly strong assumption about the exponential utility function, this would not suffice to close the gap between the $s_{\min }$ and $s_{\max }$ values. In this example, more than half of the $\left[s_{\min }, s_{\max }\right]$ interval is attributable to uncertainty about landowners' degree of risk aversion. The key strength of the SD approach is its minimal assumptions: the SD-based $s_{\min }$ and $s_{\max }$ values bound the optimal payment for all well-behaved utility functions and all levels of risk aversion.

If data are not of sufficiently high quality, however, the minimal assumptions of SD could constitute a weakness of the method. In our empirical example, three issues arise that might trigger discrepancies: (1) the use of aggregated time series (ATS), (2) the endogeneity of observed land uses, and (3) the irreversibility and switching costs associated with land conversion. These deserve further discussion.

In many empirical applications ATS are used because farm-level data are not available, or data that are available cover too short a period or are considered of too poor quality. ATS usually consist of hectare-weighted averages over a sample of farms. This averaging over farms tends to eliminate farm-specific information. Therefore, using ATS emphasizes inter-temporal randomness common to all producers and de-emphasizes farm-specific randomness (Just and Weninger). In our study,

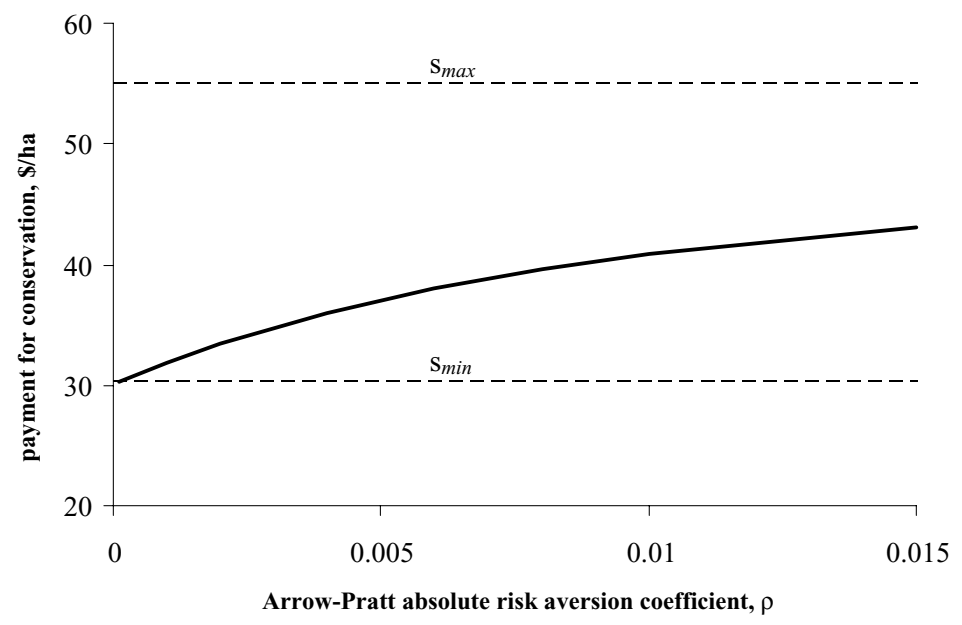

Figure 3. Impact of risk aversion on the required payment for conservation 
the impact of using ATS on net revenue distributions is expected to be small because the risk that coffee growers face is mainly associated with price volatility. Also, inter-temporal yield variability is expected to be larger than farm-specific variability. In particular, yield risk associated with crops growing in Manabí is associated with the length of the rainy season, droughts, and El Niño, which affect all farmers. In a general setting, however, farm-level variability might turn out to be more relevant and ATS should be corrected using appropriate methods (see Goodwin and Ker).

Endogeneity of observed land use is another problem in empirical studies. Specifically, the estimated revenue distributions are solely based on lands currently in production; for example, the revenue distribution for maize is estimated for the land currently growing maize. Maize yields are likely to be lower on lands less suitable for maize, such as pasture. However, the suitability of land for a particular type of production is not taken into account in revenue distribution estimates. In practice, such quality differences are difficult to deal with because we do not observe the same land in all of the different uses; this would require an experimental setting. If we could somehow adjust the revenue distributions to reflect appropriate differences in land quality, we would expect the farmers to favor current land uses. Presumably, the land currently growing shaded coffee is relatively more productive in that activity than in any alternative use. Thus, if endogeneity of land-use choices was taken into account, the estimated $s_{\min }$ and $s_{\max }$ payments would be smaller.

Finally, irreversibility of land-use decisions creates an option value when future returns are uncertain (Clarke and Reed), and this needs to be taken into account. Real-option models were developed to quantify such a premium on land value, providing more realistic information on conservation policy performance (Schatzki). However, Bulte et al. showed that the option value associated with irreversible destruction of primary forests is likely very small. Furthermore, as our example does not refer to the conservation of primary forest but of shaded coffee production as a biodiversityrich agroforest system, irreversibility in the strict sense is unlikely to be a problem. Yet, irreversible (sunk) investment expenditures occur because coffee yields and revenues are only expected to begin three years after planting. In addition, after abandoning coffee temporarily or switching to another crop, further sunk costs have to be taken into account when trying to restart coffee production (Pindyck). This situation can lead to "land-use hysteresis," where coffee, although an economically less attractive land use, is not converted to cropland due to sunk costs and uncertainty about future returns (Schatzki). Higher uncertainty increases the value of the option to convert and, thus, decreases the likelihood of conversion. Schatzki notes that changes in net returns might depend on permanent or nonpermanent shocks to yields, prices, and costs, and that the resulting net effect on returns might not follow a pure random walk. Lower correlation between shocks to alternative landuse returns would increase the option value. This issue seems of particular importance to farms with diversification possibilities, where the flexibility in choosing land use is valued. In our case study, some land-use returns are not correlated, which might result in a higher option value. Consequently, the estimated $s_{\min }$ and $s_{\max }$ payments would be smaller if irreversibility was taken into account.

In conclusion, by ignoring the effects of endogeneity and irreversibility, our estimates of the required conservation payments constitute an overestimate, which needs to be considered when interpreting $s_{\min }$ values in particular. If the effects of endogeneity and irreversibility are strong, payments below $s_{\min }$ might be effective for many risk-averse landowners. The original interpretation of the $s_{\max }$ values as conservative upper bounds still applies, but lower (and hence more efficient) $s_{\max }$ estimates could be obtained if the effects of endogeneity and irreversibility are taken into account.

\section{Summary and Conclusions}

We extended the use of stochastic dominance rules in agricultural economics by analyzing situations with full farm diversification, and applied this theory to the identification of the conservation payments needed to prevent land-use change that reduces biodiversity in developing countries. In particular, we introduced two efficiency measures for evaluating forest/agroforest land use: (1) the minimum risk-free payment $\left(s_{\min }\right)$ required to ensure that forestry is not dominated by any other land use; and (2) the minimum risk-free payment $\left(s_{\max }\right)$ guaranteeing that forestry dominates all other land uses. Large values of $s_{\min }$ represent land uses that are least risk efficient, while small values of $s_{\max }$ represent 
risk-efficient land uses that nearly dominate all other land uses. Knowledge of $s_{\min }$ and $s_{\max }$ helps to identify intervention strategiespayments for conservation- that can be implemented efficiently.

The methodology was applied to a West Ecuador case study, where shaded coffee is compared with the most important alternative land uses in the region. Results indicate that (1) shaded coffee is not a risk-efficient land use, no matter whether diversification is possible or not. This goes a long way toward explaining current land uses. (2) The extant distribution of land uses has a strong impact on the required conservation payment. (3) Land-use policy interventions need to incorporate risk-hedging strategies and insurance possibilities for small farmers, instruments that are slowly developing in Ecuador's financial markets. Diversification can be used to hedge risks in shaded coffee areas. For example, it is possible to incorporate fruit trees among shaded coffee plants. The optimum crop mix for a shaded coffee parcel could be estimated with a similar approach as that used in this article, namely, using an LP program to find the optimal crop mix that minimizes $s_{\min }$ (or $s_{\max }$ ) payments given the distributions of net returns to coffee, fruit trees, maize, and so on.

While provision of risk-free payments for protecting coffee areas is one strategy, a better alternative might be to make conservation payments dependent on the coffee revenue of the farm. In such an arrangement, the conservation agent would bear part of the coffee farmers' income risk, and would benefit in the form of lower total costs for conservation as the risks cancel out when spread across many farmers and over time. Clearly, a large international conservation agency is more capable of bearing risks than a small farmer operating in a developing country. Taking the risk preferences of both landowners and the conservation agency explicitly into account would require a game-theoretic analysis, where the analytical $s_{\min }$ and $s_{\max }$ bounds characterized above would represent individual rationality conditions for the landowners. Such a gametheoretic analysis is left as a topic for future research.

Finally, our method for estimating riskefficient conservation payments could be used to derive cost curves for a variety of environmental services and for diverse climate change applications. This may be particularly apt in the case of carbon sequestration as the Kyoto Protocol allows trading carbon offsets from forestry and agricultural activities. To derive a carbon uptake cost curve, it is necessary to first define a wide range of possible portfolios and then estimate the carbon level for each. For each portfolio, there is a corresponding level of compensation (or carbon uptake costs), and that information can be used to estimate a supply curve for carbon uptake services. This is another area for future research.

$$
\begin{aligned}
& \text { [Received June 2004; } \\
& \text { accepted March 2005.] }
\end{aligned}
$$

\section{References}

Barley, D., and J.W. Richardson. "Analysis of Selected Marketing Strategies: A Whole-Farm Simulation Approach." American Journal of Agricultural Economics 67(1985):813-20.

Benítez, P.C., R. Olschewski, F. de Koning, and M. López. "Análisis Costo-beneficio de Usos del Suelo y Fijación de Carbono en Sistemas Forestales de Ecuador Noroccidental." Report TÖB TWF-30s of the German Technical Cooperation Agency, Eschborn, Germany, 2001.

Bulte, E., D.P. van Soest, G.C. van Kooten, and R.A. Schipper. "Forest Conservation in Costa Rica when Nonuse Benefits are Uncertain but Rising." American Journal of Agricultural Economics 84(2002):150-60.

Callaway, J.M., and B.A. McCarl. "The Economic Consequences of Substituting Carbon Payments for Crop Subsidies in U.S. Agriculture." Environmental and Resource Economics 7(1996):15-43.

Clarke, H.R., and W.J. Reed. "A Stochastic Analysis of Land Development and Property Valuation." Regional Science and Urban Economics 18(1988):357-81.

Cochran, M.J., L.J. Robinson, and W. Lodwick. "Improving the Efficiency of Stochastic Dominance Techniques Using Convex Set Stochastic Dominance." American Journal of Agricultural Economics 67(1985):287-95.

Collender, R.N., and D. Zilberman. "Land Allocation under Uncertainty for Alternative Specifications of Return Distributions." American Journal of Agricultural Economics 67(1985):779-86.

Deininger, K., and B. Minten. "Determinants of Deforestation and the Economics of Protection: An Application to Mexico." American Journal of Agricultural Economics 84(2002):943-60.

Echavarria, M., J. Vogel, M. Albán, and F. Meneses. The Impacts of Payments for Watershed Services in Ecuador, Emerging Lessons from Pimampiro and Cuenca. London: International 
Institute for Environment and Development (IIED), 2003.

Goodwin, B.K., and A.P. Ker. "Modeling Price and Yield Risk." In R.E. Just and R.D. Pope, eds. $A$ Comprehensive Assessment of the Role of Risk in U.S. Agriculture. London: Kluwer Academic Publishers, 2002:289-324.

Holt, C.A. and S.K. Laury. "Risk Aversion and Incentive Effects." American Economic Review, 92(2002):1644-55.

INEC. Indice de Precios al Consumidor. Serie 1967-2003. Quito: Instituto Ecuatoriano de Estadísticas y Censos, 2003.

INEC, MAG, and SICA. III Censo Nacional Agropecuario: Resultados Provinciales y Cantonales-Manabí. Quito: Instituto Ecuatoriano de Estadísticas y Censos, 2001.

Just, R.E., and R.D. Pope. "Past Progress and Future Opportunities for Agricultural Risk Research.” In R.E. Just and R.D. Pope, eds. $A$ Comprehensive Assessment of the Role of Risk in U.S. Agriculture. London: Kluwer Academic Publishers, 2002:557-77.

Just, R.E., and Q. Weninger. "Are Crop Yields Normally Distributed?" American Journal of Agricultural Economics 81(1999):287-304.

Klemme, R.M. "A Stochastic Dominance Comparison of Reduced Tillage Systems in Corn and Soybean Production under Risk." American Journal of Agricultural Economics 67(1985):550-57.

Kuosmanen, T. "Efficient Diversification According to Stochastic Dominance Criteria." Management Science 50(2004):1390-1406.

Levy, H. "Stochastic Dominance and Expected Utility: Survey and Analysis." Management Science 38(1992):555-93.

- Stochastic Dominance: Investment Decision Making under Uncertainty. Boston: Kluwer Academic Publishers, 1998.

McCarl, B.A., T.O. Knight, J.R. Wilson, and J.B. Hastie. "Stochastic Dominance over Potential Portfolios: Caution Regarding Covariance." American Journal of Agricultural Economics 69(1987):804-12.

MAG. Compendio Estadístico Agropecuario 196593. Quito: Ministerio de Agricultura y Ganadería, 1994.

Markowitz, H. "Portfolio Selection." The Journal of Finance 7(1952):77-91.

Meyer, J. "Two-Moment Decision Models and Expected Utility Maximization." American Economic Review 77(1987):421-30.

Meyer, J. and R.H. Rasche. "Sufficient Conditions for Expected Utility to Imply Mean-Standard Deviation Rankings: Empirical Evidence Concerning the Location and Scale Condition." The Economic Journal 102(1992):91-106.
Myers, N., R.A. Mittermeier, C.G. Mittermeier, G.A.B. da Fonseca, and J. Kent. "Biodiversity Hotspots for Conservation Priorities." Nature 403(2000):853-58.

Nelson, R.D., and R.D. Pope. "Bootstrapped Insights into Empirical Applications of Stochastic Dominance." Management Science 37(1991):1182-94.

Perfecto, I., A. Mas, T. Dietsch, and J. Vandermeer. "Conservation of Biodiversity in Coffee Agroecosystems: A Tri-taxa Comparison in Southern Mexico." Biodiversity and Conservation 12(2003):1239-52.

Pindyck, R.S. "Irreversibility, Uncertainty, and Investment." Journal of Economic Literature 29(1991):1110-48.

Plantinga, A.J., R. Alig, and H. Cheng. "The Supply of Land for Conservation Uses: Evidence from the Conservation Reserve Program." Resources Conservation and Recycling 31(2001):199-215.

Post, T. "Empirical Tests for Stochastic Dominance Efficiency." The Journal of Finance 58(2003):1905-31.

Robinson, L.J., and R.J. Myers. "Ordering Risky Choices." In R.E. Just and R.D. Pope, eds. $A$ Comprehensive Assessment of the Role of Risk in U.S. Agriculture. London: Kluwer Academic Publishers, 2002:41-51.

Schatzki, T. "Options, Uncertainty, and Sunk Costs: An Empirical Analysis of Land Use Change." Journal of Environmental Economics and Management 46(2003):86-105.

Shalit, H., and S. Yitzhaki. "Marginal Conditional Stochastic Dominance." Management Science 40(1994):670-84.

SICA. Estadísticas Agropecuarias. Precios Finca y Rendimientos. Quito: Ministerio de Agricultura y Ganadería, 2003.

Sohngen, B., and R. Mendelsohn. "An Optimal Control Model of Forest Carbon Sequestration." American Journal of Agricultural Economics 85(2003):448-57.

Stavins, R.N. "The Costs of Carbon Sequestration: A Revealed-Preference Approach.” American Economic Review 89(1999):9941009.

United Nations, Food and Agriculture Organization. Global Forest Resources Assessment 2000-Main Report. Rome, 2001.

van Kooten, G.C. "Economic Dynamics of Tree Planting for Carbon Uptake on Marginal Agricultural Lands." Canadian Journal of Agricultural Economics 48(2000):51-65.

Whitaker, M.D., D. Colyer, and J. Alzamora. The Role of Agriculture in Ecuadors Economic Development. Quito: Instituto de Estrategias Agropecuarias, 1990. 


\section{Appendix}

We find $s_{\min }$ under FMCSD and SMCSD by solving the following LPs:

\section{FMCSD}

$s_{\min }=\max _{\sigma, v_{g}, v_{h}} \sigma$

s.t.

$$
\sigma \leq\left(\left(v_{g} x_{g, i}^{\mathbf{w}}+v_{h} x_{h, i}^{\mathbf{w}}\right) \quad \sigma \leq \frac{1}{i}\left(\left(v_{g} x_{g, i}^{\mathbf{w} \prime}+v_{h} x_{h, i}^{\mathbf{w} \prime}\right)\right.\right.
$$$$
\left.-x_{f, i}^{\mathbf{w}}\right) i=1, \ldots, T
$$$$
v_{g}+v_{h}=1 \text { and }
$$$$
v_{g}, v_{h} \geq 0
$$

\section{SMCSD}

$s_{\min }=\max _{\sigma, v_{g}, v_{h}} \sigma$

s.t.

$$
\left.-x_{f, i}^{\mathbf{w \prime}}\right) i=1, \ldots, T
$$

$v_{g}+v_{h}=1$ and

$v_{g}, v_{h} \geq 0$
Since $\sigma$ is constrained to be less than or equal to the objective of the original max-min problem " $i=1, \ldots, T$, and since at least one of the inequalities must be binding in the optimal solution, $\sigma$ represents the minimum bound. Thus, setting portfolio weights $v_{\mathrm{g}}$ and $v_{h}$ to maximize $\sigma$ will give the solution to the max-min problem.

The objective function for the max-max problem is linear, so the LP solution gives the extreme values $v_{\mathrm{g}}=1$ and $v_{h}=0$, or vice versa. Thus, the maximum bound $\left(s_{\max }\right)$ is calculated in two steps. First, make a pair-wise comparison between forest and all other crops and find $s_{\max }$ for each comparison, following equations (10) and (11). Then, choose the larger $s_{\text {max }}$. 
Query

Q1 Author: Please check that the change retains the intended sense. 